\title{
Fundamental Principles of Laboratory Fixed Bed Reactor Design
}

Daniel A. Hickman ${ }^{1 *}$, John Degenstein ${ }^{2}$, and Fabio Ribeiro ${ }^{3}$

\author{
${ }^{1}$ The Dow Chemical Company, Midland, MI, 48674, dahickman@dow.com \\ ${ }^{2}$ School of Chemical Engineering, Purdue University, West Lafayette, IN, 47907, \\ john.degenstein@gmail.com \\ ${ }^{3}$ School of Chemical Engineering, Purdue University, West Lafayette, IN, 47907, fabio@purdue.edu \\ *Corresponding author
}




\begin{abstract}
A few important, foundational principles enable more effective discovery and development of heterogeneous catalysts. Numerous experts have documented and illustrated these principles over the past several decades, but many current practitioners fail to heed their sage advice. We revisit the concepts, which we categorize as the bed-scale phenomena of isothermality, contacting pattern ideality, isobaricity, and wetting efficiency, and the particle-scale phenomena of internal and external temperature and concentration gradients. In addition, we introduce a new public domain, web-based tool for quickly estimating the magnitude of the effects of these phenomena. Our objective is to motivate and equip our colleagues to teach these principles and to apply sound reaction engineering practices in their laboratory work.
\end{abstract}

\title{
Keywords
}

Fixed bed; packed bed; reactor; heterogeneous catalyst; reaction engineering; reactor design; mass transfer; heat transfer

\section{Introduction}

"Those who cannot remember the past are condemned to repeat it" [1]. This article intentionally deviates from the review of current advances to emphasize our current opinion, undergirded by foundational work that has accumulated over the past five decades. We feel this topic is perennially relevant. Just as each generation must teach the next generation the fundamentals of reading, so each generation of reaction engineering and catalysis practitioners must teach the next generation the fundamentals of our discipline.

In particular, this article targets an audience that lives that the interface of two disciplines, chemical reaction engineering and heterogeneous catalysis. Our objective is to provide a service to that community by highlighting the fundamental principles that must govern the experimental evaluation of heterogeneous catalyst systems at the laboratory scale. In our experience, researchers often ignore these fundamental principles. We hope that, by drawing attention to this admittedly mature knowledge base, we will remind those who have forgotten, equip those who want to collaborate in our effort to educate the next generation, and teach those who never learned these foundational principles. We begin with brief comments addressing the historical context.

\section{Historical Context}

The field of heterogeneous catalysis can trace its roots to the first half of the nineteenth century, as ably described by Robertson [2]. On the other hand, chemical reaction engineering (CRE) evolved to become a formal discipline within the field of chemical engineering in the 1940s and 1950s. Early markers of this discipline's formalization include the inaugural European Symposium on Chemical Reaction Engineering in 1957 (ISCRE History; URL: http://iscre.org/iscre_history.htm) and the publication of Levenspiel's Chemical Reaction Engineering in 1962 [3]. Levenspiel emphasized in the preface of his seminal text that 
"the goal is the successful design of chemical reactors..." In spite of the goal stated by Levenspiel and shared by many other CRE textbook authors, the topic of laboratory reactors is inconspicuous in those textbooks. While some CRE textbooks acknowledge the importance of selecting laboratory reactors that will generate accurate data useful for reactor design and provide heuristics to assist in selecting laboratory reactors [4,5], many provide no explicit mention of the importance of or methodology for selecting and designing laboratory reactors.

\section{Earlier Reviews}

Many have provided guidance regarding the selection, design, and operation of laboratory reactors. Using a gas-liquid reaction over a powdered catalyst relevant to his work at Mobil, Weekman focused on the decision process for selecting a laboratory reactor, providing heuristics for choosing from a menu of several potential options [6]. When Rase and Perkins [7] introduced their implementation of Hougen's recirculation reactor concept [8], they emphasized the importance of eliminating temperature and diffusion gradients in order to independently study the effects of each system variable. Smith emphasized the reactor design dilemma caused by non-isothermal heterogeneous catalytic reactors [9]. While these papers focused on concepts rather than quantitative criteria, numerous authors tackled individual components of the macroscopic problem, but, in 1971, Mears provided the first comprehensive review with quantitative guidance for laboratory fixed bed reactor applications [10]. Dommeti et al. later showed the limitations of the Mears criterion for interphase transport [11]. More recent publications have expanded the scope to address additional factors important in trickle bed reactors, such as reviews by Sie [12], Mary et al. [13], Mederos et al. [14], and Bej [15].

\section{Scope of This Review}

The 45-year-old paper by Mears provides the launching point for our primer, which will specifically address laboratory scale fixed bed reactors, including both integral reactors and recycle reactors. Analogous concepts and principles apply to other systems, such as stirred tank slurry reactors [16] and single-phase tubular flow reactors [17], but those systems are outside of the scope of our current review.

Common laboratory fixed bed reactors include integral reactors (tubing packed with catalyst) and recycle reactors, which can use an external recycle scheme based on a packed tubular reactor coupled with a recycle pump or compressor or an internal recycle scheme. Internal recycle reactors typically used for gas-solid systems have varied designs and are informally named after their inventors (Berty [18], Caldwell [19], and Carberry [20]), but all have the objective of testing commercial-scale catalyst particles contained in a porous basket. We differentiate these reactors based on the mixing efficiency and the superficial velocities that can be achieved in the catalyst beds, with higher velocities preferred in order to minimize external transport gradients. Users of these reactors must carefully evaluate these reactors to ensure the performance is sufficient to generate data of the required quality for a particular application [19,21-25]. For gas-liquid-solid systems, the Robinson-Mahoney design [26] is the most popular option for testing fixed bed catalysts under well-mixed conditions.

In an effort to miniaturize laboratory fixed bed reactors, one new vista for laboratory fixed bed reactors involves reactors with channel-to-particle diameter ratios approaching unity. Recent publications [27- 
29] build on the old idea of a "single pellet string reactor" [30,31] by shrinking the reactor diameter to approach the diameter of the catalyst particles, resulting in so-called packed bed microreactors or microchannel fixed bed reactors. While our present review does not address these cases explicitly, we refer interested readers to these publications. Although the principles in our review equally apply to these cases, the specific correlations for phenomena such as gas-liquid mass transfer or axial dispersion and the evaluation of the importance of wall effects are special cases that must be addressed accordingly.

Next, we will review the guiding principles for laboratory fixed bed reactors and point the reader to useful references while avoiding the reproduction of quantitative expressions previously published in the literature. We close by illustrating the application of these principles to an example system.

\section{Guiding Principles}

In this section, we address bed-scale (interparticle) phenomena first, followed by particle-scale (interphase and intraparticle) phenomena.

\section{Bed-Scale Phenomena}

Researchers should design and operate their laboratory scale reactors to achieve isothermality, contacting pattern ideality, and isobaricity on the scale of the catalyst bed. The catalyst in gas-liquidsolid systems should be fully wetted.

\section{Isothermality}

For integral fixed bed reactors, isothermality is typically the most difficult performance criterion to satisfy. Mears provides a useful criterion, defining isothermality to be achieved when the average reaction rate at the cross-section of the hot spot in an integral reactor is within $5 \%$ of the rate at the wall temperature [32]. This criterion applies equally to all possible fluid phase scenarios. The primary challenge to implement this criterion involves choosing appropriate correlations for the wall heat transfer coefficient and the bed effective thermal conductivity that apply for the potentially lower linear velocities and smaller particles used in the laboratory setting. For recycle reactors, isothermality is achieved by attaining a sufficiently high recycle ratio so that the single pass adiabatic temperature rise is negligible [23].

\section{Contacting Pattern Ideality}

For integral fixed bed reactors, the ideal contacting pattern is plug flow. Mears provides a conservative criterion for plug flow [33]. In addition to relaxing the Mears plug flow criterion, Gierman observed that, in the limit of low flow rates, the Bodenstein number asymptotically reaches a constant value [34]. Combining those two factors, Sie offers an alternative plug flow criterion based on Gierman's assumption and observation [12]. Unlike the criterion from Mears, this latter criterion does not require an estimate of the axial dispersion coefficient since that value is implicit in the constant Bodenstein number at low flow rates.

Sie emphasizes that the above criteria assume a randomly packed bed with no variability in the velocity profile as a function of the bed radius [12]. In fact, laboratory scale reactors are very prone to wall 
effects because of the greater void fraction near the wall. Sie proceeds to show that, for systems in which the only fluid is a gas, the traditional rule of thumb that the tube to particle diameter exceed 10 is invalid, and ratios as small as 5 or less may still give plug flow performance in spite of wall effects because radial dispersion "erases" the effect of the radial velocity profile. However, because diffusion in liquids is four orders of magnitude slower than in gases, reactors containing liquid should maintain a tube to particle diameter ratio of at least 20.

Another factor often overlooked with respect to the contacting pattern relates to the unintended consequences of inert diluents in a catalyst bed. On occasion, the researcher may choose to dilute the bed with catalytically inert particles in order to reduce the rate of heat generation per bed volume for an exothermic reaction, thereby distributing the heat sources over a larger volume and providing more wall heat transfer area for the heat evolved or consumed by reaction. However, excessive dilution can result in local bypassing that results in deviations from plug flow performance, especially at high conversions $[35,36]$.

For recycle reactors, a sufficiently high recycle ratio ensures a well-mixed system, the appropriate ideal contacting pattern for these reactors.

\section{Isobaricity}

For integral fixed bed reactors, isobaricity (negligible pressure drop) is important for systems containing a gas phase. For gas-solid systems, the reactant partial pressures are the driving force terms in the rate expressions. For gas-liquid-solid systems, the partial pressure of a sparingly soluble gas phase reactant, such as hydrogen in a hydrogenation, is directly proportional via Henry's Law to the concentration of the dissolved gas phase component and, thus, is typically a driving force term in the rate expression.

Consequently, achieving negligible pressure drop through the catalyst bed enables the analysis to avoid accounting for or correcting for pressure drop [37], which is not typically measured accurately in small, laboratory-scale reactors. One suggested rule of thumb is that the pressure drop should not exceed $20 \%$ of the inlet pressure [38]. For liquid-filled systems, pressure drop is typically negligible and of little importance with respect to reaction kinetics.

For internal recycle reactors, a negligible pressure drop is the necessary corollary of a high recycle ratio. For external recycle reactors, which use a pump or compressor, if a gas phase is present, the previous discussion associated with integral fixed bed reactors applies.

\section{Wetting Efficiency}

For gas-liquid-solid integral fixed beds operated as trickle beds, catalyst wetting efficiency is a welldocumented but often overlooked performance criterion [39]. We could write an entire review article on this topic alone, which is primarily a concern with small systems, especially laboratory-scale trickle bed reactors. In summary, to achieve the desired state of each catalyst particle engulfed in a continually replenished film of flowing liquid, the researcher has two options: operate at sufficiently high superficial fluid velocities, typically only achievable in a recycle reactor at the laboratory scale [40], or dilute the catalyst bed with inert fine particles [41]. We conclude this brief discussion with four additional comments on this topic. (1)Loading a tube with a mixture of catalyst and inert fines must be executed 
carefully [42]. (2) Diluting a catalyst bed with inert fines does not guarantee perfect wetting and decoupling of all hydrodynamic effects $[43,44]$. (3) Appropriate pre-wetting of a trickle bed is an important precursor to fully wetted, reproducible operation. While this phenomenon has been studied extensively in systems without inert fines [45-52], we are not aware of similar reports for small-scale systems with inert fines, but we are aware of observations of similar effects in diluted beds. (4) While efforts to model the fractional catalyst wetting may lead to a challenging and educational doctoral thesis, we advise against such pursuits if the objective is to evaluate a catalyst or design a larger scale reactor.

Similar wetting concerns apply to external recycle reactors with differential or low conversions, but either dilution with fines or sufficiently high liquid superficial velocities can ensure high wetting efficiencies [40]. On the other hand, for batch or continuous reactors with catalyst contained in a basket and rapid fluid circulation using a gas-dispersing impeller, such as the Robinson-Mahoney design [26], immersion of the catalyst in the liquid ensures complete wetting.

\section{Particle-Scale Phenomena}

In addition to eliminating bed-scale (interparticle) gradients, a well-designed laboratory reactor will also minimize external (interphase) gradients and either eliminate or appropriately manage internal (intraparticle) gradients. While we recommended that researchers always strive to eliminate external (interphase) temperature and concentration gradients, we offer two alternatives for managing internal (intraparticle) concentration and thermal gradients: (1) the reactor design can utilize sufficiently small particles to avoid those gradients or (2) the laboratory reactor can use catalyst particles identical to those in the full-scale reactor. Kinetic data generated using the latter option constitute apparent kinetics, where the measured rates are the consequence of the combined effects of intraparticle transport phenomena and intrinsic reaction kinetics. For reactor scaling purposes, measuring apparent kinetics is sufficient as long as the catalyst is not changed, including its size and porosity. The former method is preferred for the early stages catalyst discovery and development, while the latter method is most relevant during later stages of catalyst development as well as for reactor design and optimization.

In designing a new system, we rely on literature correlations to compute external heat and mass transfer gradients, and we employ well-known calculations to estimate internal resistances. These effects are equally important in both integral and recycle fixed bed reactors. We advise researchers to follow their initial calculations with experiments designed to verify those calculations, such as comparing catalyst performance with crushed and whole particles to confirm the absence of intraparticle transport limitations or varying the amount of catalyst with a fixed space velocity to ensure the absence of strong external effects.

\section{External}

Dwivedi and Upadhyay offer a mass transfer correlation [53] of the Chilton-Colburn type [54]. Applying the Chilton-Colburn analogy provides an estimate for the heat transfer coefficient as well. Combining these parameters with the measured or estimated local reaction rate per catalyst particle and the bulk fluid concentration of the limiting reactant enables computation of the external concentration and temperature gradients around a single catalyst particle. Reasonable criteria for declaring the system free 
of external gradients are a concentration change of less than $5 \%$ relative to the bulk concentration and a temperature change of less than $1^{\circ} \mathrm{C}$. Alternatively, Mears offers criteria using a constraint based on a maximum deviation of $5 \%$ in the rate relative to the intrinsic rate with no transport limitations around the particle [10]. Carberry also defines criteria for evaluating external gradients, where concentration gradients are deemed significant if the observed rate exceeds $1 \%$ of the maximum possible mass transfer rate and temperature gradients are deemed significant if the particle surface temperature deviates from the bulk absolute temperature by more than $1 \%$ [5].

\section{Internal}

Given the observed or estimated reaction rate over a catalyst particle of known physical properties and the assumption of a pseudo-first order reaction in the limiting reactant, we can compute a reasonable estimate of the concentration and temperature gradients within that particle. Satterfield [55] estimates the effective diffusivity from the molecular diffusivity, particle porosity, and tortuosity, as well as a Knudsen diffusivity [56] for gaseous systems with small pores and a pore construction factor for liquid systems $[57,58]$. Aris identified a useful definition for the characteristic length for diffusion [59], enabling calculation of the isothermal effectiveness factor from the Thiele modulus, which is the square root of the Weisz-Prater modulus [60] divided by the effectiveness factor. Given the Thiele modulus, we can also compute the minimum internal concentration of the limiting reactant [3], and we can compute the corresponding core temperature in the particle by balancing heat generation with removal via conduction [61]. This entire analysis assumes a nearly isothermal particle, which is the most common scenario in practice, but Weisz and Hicks offer a useful check for the possibility of multiple steady-states based on a thermicity factor that is easily calculated using the conditions at the catalyst surface [62].

When screening catalyst materials as small granules, catalyst developers should confirm the absence of intraparticle effects. Reasonable targets are internal and external temperature gradients less than $1^{\circ} \mathrm{C}$, an isothermal effectiveness factor that exceeds $95 \%$, and an external concentration gradient that is less than $5 \%$ of the bulk concentration of the limiting reactant. Alternatively, Mears provides criteria for achieving an effectiveness factor greater than $95 \%$ and sufficiently isothermal performance [10].

\section{Public Domain Tool}

The body of this review outlines the methodology for checking a laboratory reactor and catalyst system for undesirable bed-scale and particle-scale gradients. While this procedure is straightforward, collecting the relevant equations and physical properties information is tedious and prone to errors that can easily propagate, resulting in an incorrect analysis. Reaction engineers at The Dow Chemical Company developed a spreadsheet tool in the late 1990s to automate these calculations and eliminate most of the sources of error in these analyses. In order to promote the best practice of routinely performing these simple calculations, the authors of this review have created a similar public domain tool, developed and supported at Purdue University. We have named this tool GradientCheck (www.GradientCheck.com). We encourage the reaction engineering and catalysis community to use this tool to accomplish the important objectives outlined in this article. 


\section{Case Studies}

We illustrate these principles using two examples from the literature by using our GradientCheck tool. We hope that the availability of this tool will equip our colleagues in the reaction engineering and catalysis community to avoid the design and operation of non-ideal laboratory reactors for heterogeneous catalyst systems.

\section{Example 1}

Weisz and Swegler experimentally measured the effect of particle size on the rate and selectivity for a series of cyclohexane dehydrogenation reactions over chromia-alumina catalyst particles with three different sizes [63]. Because the original work did not use a typical continuous fixed bed reactor, we choose arbitrary bed dimensions and assumed differential conversion (1\%) to illustrate the importance of bed-scale effects.

With respect to the particle-scale effects, we compare the measured and computed effectiveness factors in Table 1. Given the uncertainties and approximations inherent in this analysis, the agreement between the calculated and measured values is acceptable. The three figures show the complete input table and selected output for the largest particle case. Figure 2 and Figure 3 reveal that intraparticle concentration and external temperature gradients are both significant for this scenario. Furthermore, application of the Mears criterion indicates that the radial bed-scale temperature gradient would be significant, resulting in non-isothermal behavior of our hypothetical 1-cm inner diameter reactor.

This example highlights the most common transport issues in gas-solid fixed bed systems: internal (intraparticle) diffusion, external (interphase) heat transfer, and bed-scale (interparticle) heat transfer often prevent accurate measurement of intrinsic catalyst behavior in laboratory reactor data.

\section{Example 2}

Sharma et al. developed a kinetic model and reactor model for fixed bed oxidation of $\mathrm{n}$-butane to maleic anhydride and compared the reactor model predictions with pilot plant reactor performance [64]. We provide the inputs for the experimental conditions in Figure 3 from that reference via the input file linked from the "How to Use" page associated with the GradientCheck tool. Our calculations predict minimal particle-scale gradients but confirm the extreme deviation from isothermality in that reactor. This example illustrates the primary reason that large fixed bed reactors are generally not the appropriate vessels for generating kinetic data. In a non-isothermal reactor like the one in this example, the accuracy of any kinetic parameters fit to pilot data is inextricably linked to the accuracy of the heat transfer model used to simulate the reactor.

\section{Conclusion}

In closing, we hope this brief review stimulates our colleagues in the reaction engineering and heterogeneous catalysis community to redouble efforts to exercise discipline in the design and operation of laboratory fixed bed reactors for catalyst screening, catalyst and process development, and measurement of reaction kinetics. This review outlines the key principles and highlights our new public domain tool, which we hope will prove useful for teaching and for guiding experimental activities. 


\section{Acknowledgements}

The GradientCheck tool was inspired during Fabio Ribeiro's summer sabbatical at The Dow Chemical Company. The authors thank The Dow Chemical Company for sponsoring Fabio's term at Dow. We also acknowledge Von Landon, the creator of the first version of Dow's internal tool and supporting documentation, which provide the basis for many aspects of the public domain GradientCheck tool and this article. Support from the Department of Energy, Office of Basic Energy Sciences, Chemical Sciences, under Grant DE-FG02-03ER15408 is gratefully acknowledged.

\section{Table and Figures}

Table 1. Comparison of measured and computed effectiveness factors for cyclohexane dehydrogenation.

$\begin{array}{cccc}\text { Radius }(\mathrm{cm}) & \text { Rate }(\mathrm{mol} / \mathrm{kg} / \mathrm{s}) & \begin{array}{c}\text { Effectiveness factor } \\ \text { Weisz \& Swegler } \\ \text { (measured) }\end{array} & \begin{array}{c}\text { GradientCheck } \\ \text { (calculated) }\end{array} \\ 0.05 & 1.46 \times 10^{-3} & 1.00 & 0.97 \\ 0.184 & 9.58 \times 10^{-4} & 0.66 & 0.77 \\ 0.31 & 7.03 \times 10^{-4} & 0.48 & 0.58\end{array}$




\section{Gradient $\sqrt{ }$ (GradientCheck) for Heterogeneous Catalysis:}

By using this tool you agree to the terms of the license.

\begin{tabular}{|c|c|c|c|c|c|c|}
\hline Open JSON Input File $\mathrm{Cl}$ & Choose File & \multicolumn{5}{|c|}{160122 Weisz and Swegler_big.json } \\
\hline \multirow{3}{*}{\multicolumn{2}{|c|}{$\begin{array}{l}\text { Reaction Phase: } \\
\text { Temperature }\left(T_{b} \& T_{w}\right) \text { : } \\
\text { Pressure }(P) \text { : }\end{array}$}} & \multicolumn{5}{|c|}{ Gas Phase $\mathbf{V} /$ default: Gas Phase } \\
\hline & & \multicolumn{2}{|c|}{751.65} & \multicolumn{3}{|l|}{ l/K } \\
\hline & & \multicolumn{2}{|c|}{1} & \multicolumn{3}{|c|}{ / bar } \\
\hline \multicolumn{2}{|l|}{ Reactor Radius $\left(\mathrm{R}_{\mathrm{r}}\right)$ : } & \multicolumn{2}{|c|}{0.005} & \multicolumn{3}{|c|}{ / m -- [Accepts scientific notation e.g. 1e-3] } \\
\hline \multirow{2}{*}{\multicolumn{2}{|c|}{$\begin{array}{l}\text { Bed Length }\left(L_{b}\right) \text { : } \\
\text { Catalyst Particle Shape: }\end{array}$}} & \multicolumn{2}{|l|}{0.0182} & \\
\hline & & \multicolumn{2}{|c|}{ Spheres V } & \\
\hline \multicolumn{2}{|l|}{ Particle Radius $\left(R_{p}\right)$ : } & \multicolumn{2}{|c|}{0.0031} & \multicolumn{3}{|l|}{$/ \mathrm{m}$} \\
\hline \multirow{2}{*}{\multicolumn{2}{|c|}{$\begin{array}{l}\text { Observed Reaction Rate }\left(\mathrm{r}_{\mathrm{obs}}\right) \text { : } \\
\text { Enthalpy of Reaction }\left(\Delta \mathrm{H}_{\mathrm{rxn}}\right)\end{array}$}} & \multicolumn{2}{|c|}{$7 e-4$} & \multicolumn{3}{|c|}{ 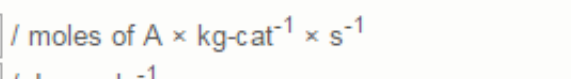 } \\
\hline & & \multicolumn{2}{|l|}{218000} & \multicolumn{3}{|c|}{$/ \mathrm{J} \times \mathrm{mole}^{-1}$} \\
\hline Reaction Order (n) & & \multicolumn{2}{|l|}{$1 \mathbf{v}$} & \\
\hline Activation Energy $\left(\mathrm{E}_{\text {app }}\right)$ & & \multicolumn{2}{|l|}{$2.51 \mathrm{e} 5$} & \multicolumn{3}{|c|}{$/ \mathrm{J} \times \mathrm{mole}^{-1}$} \\
\hline Conversion $\left(\mathrm{X}_{\mathrm{A}}\right)$ & & \multicolumn{2}{|c|}{0.01} & \multicolumn{3}{|c|}{ / unitless (0 to 1$)$} \\
\hline \multicolumn{2}{|c|}{ Catalyst Bulk Density ( $\left.\rho_{\text {bulk }}\right)$ : } & \multicolumn{2}{|c|}{1000} & \multicolumn{3}{|c|}{$/ \mathrm{kg} \times \mathrm{m}^{-3}$ [usually $\left.500-1500\right]$} \\
\hline Catalyst Void Fraction $(\varepsilon)$ : & & 0.36 & & $/(0$ & 1) [often $0.35-0.45$ ( & (default 0.4)] \\
\hline Catalyst Thermal Conduct & ctivity $\left(k_{p}\right):$ & 0.2 & & I W & $\mathrm{m}^{-1} \times \mathrm{K}^{-1}$ [often 0.1 & $13-0.25]$ \\
\hline Catalyst Surface Area $\left(\mathrm{S}_{\mathrm{ir}}\right.$ & $\left.S_{\text {int }}\right): \quad[$ & 180 & & $/ \mathrm{m}^{2}$ & $\times \mathrm{g}^{-1}$ & \\
\hline Catalyst Pore Volume $\left(V_{p}\right.$ & (pore): & $2.58 \mathrm{e}-7$ & & $/ \mathrm{m}^{3}$ & $\times \mathrm{g}^{-1}$ & \\
\hline Catalyst Pore Tortuosity ( $T$ & $(\mathrm{~T}):$ & 4 & & I uni & less [often 3-7 for por & rous catalysts] \\
\hline Number of Reactants: On & ne $\mathbf{r}$ & & & & Number of Products: & One $\mathbf{r}$ \\
\hline & $\underline{\text { React }}$ & $\operatorname{ain} A$ & Produ & & Diluent C & \\
\hline Inlet Mole Fractions: & 0.99 & & 0.01 & & 0 & / must add to 1 \\
\hline Fluid Viscosity $\left(\mu_{\mathrm{f}}\right)$ : & 0.000017 & & 0.000017 & & 0.000017 & $/ \mathrm{kg} \times \mathrm{m}^{-1} \times \mathrm{s}^{-1}$ \\
\hline Heat Capacity $\left(\mathrm{C}_{\mathrm{p}}\right)$ : & 3089.4 & & 2407.3 & & 2407.3 & $/ \mathrm{J} \times \mathrm{kg}^{-1} \times \mathrm{K}^{-1}$ \\
\hline Thermal Conductivity $\left(k_{f}\right)$ : & 0.04782 & & 0.108 & & 0.108 & $/ \mathrm{W} \times \mathrm{m}^{-1} \times \mathrm{K}^{-1}$ \\
\hline Diffusion Volume $\left(\Sigma_{v, i}\right)$ : & 123 & & 90.9 & & 90.9 & Estimate $\Sigma_{v, i}$ \\
\hline Molecular Weight (MW): & 84.2 & & 78.1 & & 78.1 & $/ \mathrm{g} \times \mathrm{mol}^{-1}$ \\
\hline
\end{tabular}

Figure 1. Input data for largest particles in last row of Table 1. 


\begin{tabular}{l|l|l|l|l} 
& \multicolumn{1}{c}{ Bed Average } & \multicolumn{1}{c}{ Bed Inlet } & \multicolumn{1}{c}{ Bed Outlet } \\
Weisz-Prater Modulus ( $\left.\mathrm{M}_{\text {WP }}\right):$ & 0.927 & 0.927 & 0.927 & / unitless \\
Thiele Modulus $\left(\mathrm{M}_{\mathrm{T}}\right):$ & 1.26 & 1.26 & 1.26 & / unitless \\
Effectiveness Factor $(\mathrm{\eta}):$ & 0.584 & 0.584 & 0.584 & / unitless
\end{tabular}

External Concentration Gradient:

External Temperature Gradient:

Internal Temperature Gradient:

Prater Number $(\beta)$ :

\begin{tabular}{|l|l}
\hline 0.195 & $/ \%$ \\
\hline-2.23 & $/ \mathrm{K}$ \\
\hline-0.652 & $/ \mathrm{K}$ \\
\hline-0.00183 & $/$ unitless \\
\hline $7.62 \mathrm{e}-5$ & $/ \mathrm{m}^{3} \times \mathrm{kg}-\mathrm{cat}^{-1} \times \mathrm{s}^{-1}$ \\
\hline 0.36 & $/$ moles of $\mathrm{A} \times \mathrm{kg}-\mathrm{cat}^{-1} \times \mathrm{s}^{-1}$
\end{tabular}

Intrinsic ( $1^{\text {st }}$ Order) Rate Constant $\left(k_{\text {int }}\right)$ :

Max Possible Diffusion-Limited Rate $\left(r_{\max }\right)$ :

\section{-Bed Scale Gradients}

Axial Dispersion Coefficient $\left(\mathrm{D}_{\text {axial }}\right)$

Radial Dispersion Coefficient $\left(D_{\text {rad }}\right)$ :

Pressure Drop Across Bed $(\Delta \mathrm{P})$ :

Effective Radial Thermal Conductivity $\left(\mathrm{k}_{\mathrm{re}}\right)$ :

Wall Heat Transfer Coeff $\left(h_{w}\right)$ :

Internal Heat Transfer Coeff $\left(h_{\mathrm{i}}\right)$

Axial Temperature Change $\left(\Delta T_{\text {axial }}\right)$

\begin{tabular}{|l|l}
\hline $2.49 \mathrm{e}-4$ & $/ \mathrm{m}^{2} \times \mathrm{s}^{-1}$ \\
\hline $4.81 \mathrm{e}-5$ & $/ \mathrm{m}^{2} \times \mathrm{s}^{-1}$ \\
\hline $1.47 \mathrm{e}-5$ & $/$ bar
\end{tabular}

\begin{tabular}{|l|l}
\hline 0.306 & $/ \mathrm{W} \times \mathrm{m}^{-1} \times \mathrm{K}^{-1}$ \\
\hline 85.3 & $/ \mathrm{W} \times \mathrm{m}^{-2} \times \mathrm{K}^{-1}$ \\
\hline 63.3 & $/ \mathrm{W} \times \mathrm{m}^{-2} \times \mathrm{K}^{-1}$ \\
\hline-12.1 & $/ \mathrm{K}$ \\
\hline
\end{tabular}

Figure 2. Tabulated results for particle-scale (top) and bed-scale (bottom) evaluation of largest particles in last row of Table 1.

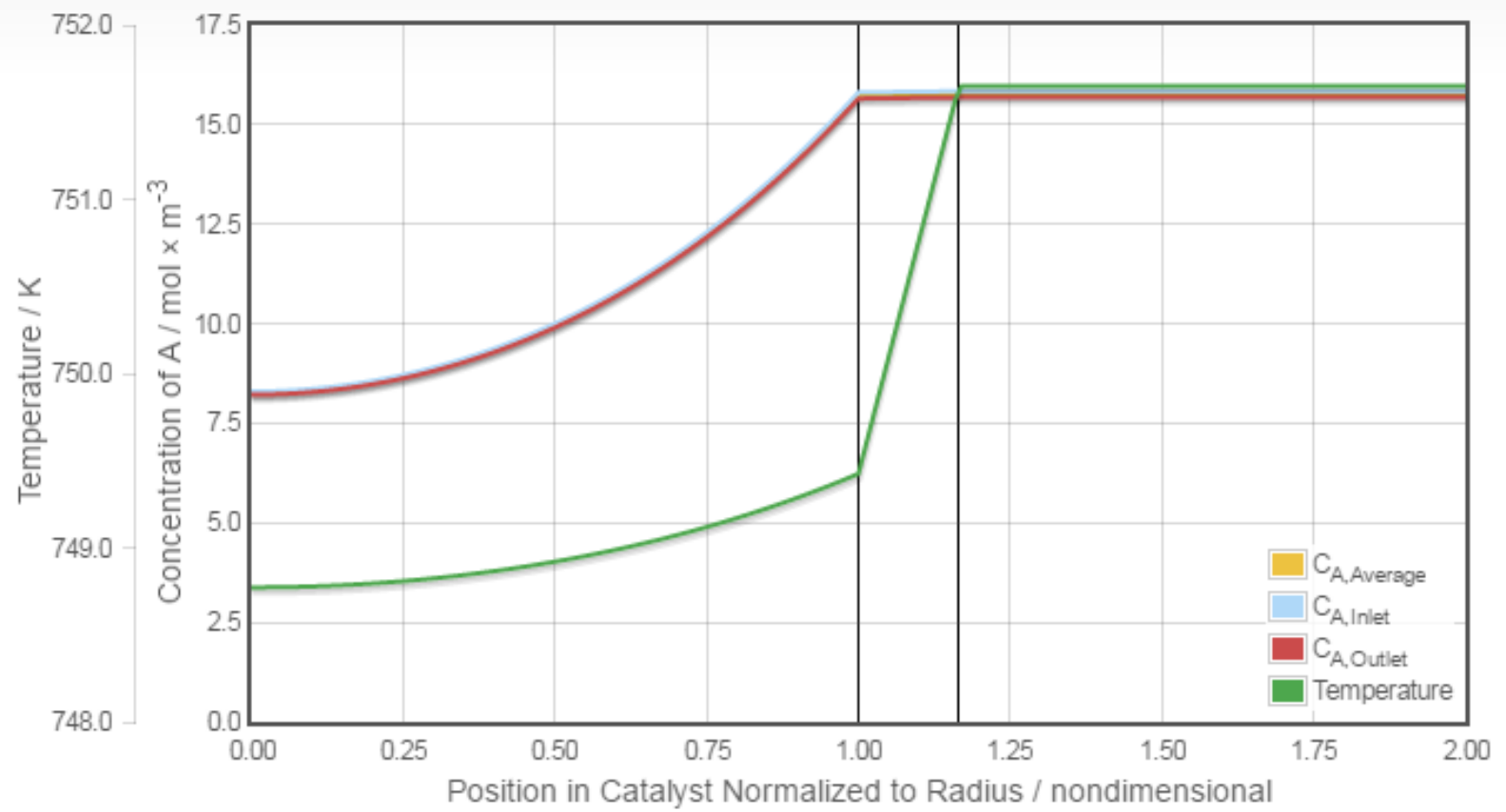

Figure 3. Graphical results for particle-scale evaluation of largest particles in last row of Table 1. 


\section{Table and Figure Captions}

Table 1. Comparison of measured and computed effectiveness factors for cyclohexane dehydrogenation.

Figure 1. Input data for largest particles in last row of Table 1.

Figure 2. Tabulated results for particle-scale (top) and bed-scale (bottom) evaluation of largest particles in last row of Table 1.

Figure 3. Graphical results for particle-scale evaluation of largest particles in last row of Table 1.

\section{Annotations}

\section{Special Interest $(*)$}

11. This paper identifies conditions under which the Mears diagnostic test may give misleading results for the interphase transport limitations.

12. Sie shows that radial mixing and diffusion may counteract the axial dispersion resulting from wall flow at low bed-to-particle diameter ratios for gas-solid fixed beds.

34. Gierman provides a global correlation between the Reynolds number and Bodenstein number that gives asymptotic limits at the low flows in small laboratory reactors, simplifying the assessment of axial dispersion.

35. Excessive bed dilution can lead to a non-ideal contacting pattern at high conversions.

41. This paper offers one of the earliest examples that clearly demonstrates the effectiveness of bed dilution with inert fines to enable essentially complete catalyst wetting in a laboratory scale trickle bed reactor.

\section{Outstanding Interest (**)}

10. Mears provides an excellent early summary of diagnostic tests for evaluating a fixed bed reactor for intraparticle, interphase, and interparticle transport limitations.

16. Bourne's tutorial on the role of mixing in affecting selectivity in single-phase and two-phase stirred tank reactors is essential reading for anyone using liquid, gas-liquid, and liquid-liquid stirred tank reactors.

\section{References}

1. Santayana G: The Life of Reason: The Phases of Human Progress, vol 1. New York: Dover Publications, Inc.; 1980.

2. Robertson AJB: Early history of catalysis. Platinum Met. Rev. 1975, 19:64-69.

3. Levenspiel O: Chemical Reaction Engineering: An Introduction to the Design of Chemical Reactors. New York: John Wiley and Sons, Inc.; 1962. 
4. Fogler HS: Elements of Chemical Reaction Engineering edn 2nd. Englewood Cliffs, New Jersey: Prentice Hall; 1992.

5. Carberry JJ: Chemical and Catalytic Reaction Engineering. New York: McGraw-Hill Book Company; 1976.

6. Weekman VW: Laboratory reactors and their limitations. AIChE Journal 1974, 20:833-840.

7. Perkins TK, Rase HF: An improved experimental reactor for applied kinetic studies. AIChE Journal 1958, 4:351-355.

8. Hougen OA: Reaction kinetics in chemical engineering: American Institute of Chemical Engineers; 1951.

9. Smith JM: Kinetics and reactors - The engineer's dilemma. The Canadian Journal of Chemical Engineering 1970, 48:142-146.

**10. Mears DE: Tests for Transport Limitations in Experimental Catalytic Reactors. 1971, 10:541-547. Mears provides an excellent early summary of diagnostic tests for evaluating a fixed bed reactor for intraparticle, interphase, and interparticle transport limitations.

*11. Dommeti SMS, Balakotaiah V, West DH: Analytical Criteria for Validity of Pseudohomogeneous Models of Packed-Bed Catalytic Reactors. Ind. Eng. Chem. Res. 1999, 38:767-777.

This paper identifies conditions under which the Mears diagnostic test may give misleading results for the interphase transport limitations.

*12. Sie ST: Advantages, Possibilities, and Limitations of Small-Scale Testing of Catalysts for Fixed-Bed Processes. In Deactivation and Testing of Hydrocarbon-Processing Catalysts. Edited by O'Connor P, Takatsuka T, Woolery GL: American Chemical Society; 1996:6-41. ACS Symposium Series, vol 634.]

Sie shows that radial mixing and diffusion may counteract the axial dispersion resulting from wall flow at low bed-to-particle diameter ratios for gas-solid fixed beds.

13. Mary G, Chaouki J, Luck F: Trickle-Bed Laboratory Reactors for Kinetic Studies. In International Journal of Chemical Reactor Engineering. Edited by; 2009. vol 7.]

14. Mederos FS, Ancheyta J, Chen J: Review on criteria to ensure ideal behaviors in trickle-bed reactors. Applied Catalysis A: General 2009, 355:1-19.

15. Bej SK: Performance Evaluation of Hydroprocessing Catalysts: A Review of Experimental Techniques. Energy \& Fuels 2002, 16:774-784.

**16. Bourne JR: Mixing and the Selectivity of Chemical Reactions. Organic Process Research \& Development 2003, 7:471-508.

Bourne's tutorial on the role of mixing in affecting selectivity in single-phase and two-phase stirred tank reactors is essential reading for anyone using liquid, gas-liquid, and liquid-liquid stirred tank reactors.

17. Hickman DA, Sobeck DD: Liquid Phase Process Characterization. In Micro Instrumentation. Edited by Koch MV, VandenBussche KM, Chrisman RW: WILEY-VCH Verlag GmbH \& Co. KGaA; 2007:407429.

18. Berty JM: Recycle Reactors, What Are These, Why and How are These Used? In 1992 AlChE Annual Meeting. Edited by. Miami Beach, FL; 1992.

19. Caldwell L: An improved internal gas recirculation reactor for catalytic studies. Applied Catalysis 1983, 8:199-213.

20. Carberry JJ: Designing Laboratory Catalytic Reactors. Industrial \& Engineering Chemistry 1964, 56:39-46.

21. Broucek R: Falsification of kinetic parameters by incorrect treatment of recirculation reactor data. Chemical Engineering Science 1983, 38:1349-1350.

22. Wedel S, Villadsen J: Falsification of kinetic parameters by incorrect treatment of recirculation reactor data. Chemical Engineering Science 1983, 38:1346-1349. 
23. Gianetto A, Dümpelmann R, Baiker A: Criteria for gradientless operation of internal recycle reactors. Chemical Engineering Science 1992, 47:2665-2670.

24. Berty JM: Comments on the paper "An Improved Gas Recirculation Reactor for Catalytic Studies", by L. Caldwell, Applied Catalysis, 8 (1983) 199. Applied Catalysis 1983, 8:289-291.

25. Caldwell L: Reply to comments by J.M. Berty on the paper "An Improved Internal Gas Recirculation Reactor for Catalytic Studies", applied catalysis, applied catalysis, 8 (1983) 199. Applied Catalysis 1983, 8:293-294.

26. Mahoney JA, Robinson KK, Myers EC: Catalyst evaluation with the gradientless reactor. CHEMTECH 1978, 8:758-763.

27. Kluson DP, Müller A, Petschick J, Lange R: Model-Based Investigation of a Pellet String Reactor. Procedia Engineering 2012, 42:1189-1201.

28. Langsch R, Zalucky J, Haase S, Lange R: Investigation of a packed bed in a mini channel with a low channel-to-particle diameter ratio: Flow regimes and mass transfer in gas-liquid operation. Chemical Engineering and Processing: Process Intensification 2014, 75:8-18.

29. Haase $S$, Weiss M, Langsch R, Bauer T, Lange R: Hydrodynamics and mass transfer in three-phase composite minichannel fixed-bed reactors. Chemical Engineering Science 2013, 94:224-236.

30. Scott DS, Lee W, Papa J: The measurement of transport coefficients in gas-solid heterogeneous reactions. Chemical Engineering Science 1974, 29:2155-2167.

31. Šolvová O, Schneider P: Axial dispersion in single-pellet-string columns packed with cylindrical particles. Chemical Engineering Science 1994, 49:401-408.

32. Mears DE: Diagnostic criteria for heat transport limitations in fixed bed reactors. Journal of Catalysis 1971, 20:127-131.

33. Mears DE: The role of axial dispersion in trickle-flow laboratory reactors. Chemical Engineering Science 1971, 26:1361-1366.

*34. Gierman H: Design of laboratory hydrotreating reactors: Scaling Down of Trickle-flow Reactors. Applied Catalysis 1988, 43:277-286.

Gierman provides a global correlation between the Reynolds number and Bodenstein number that gives asymptotic limits at the low flows in small laboratory reactors, simplifying the assessment of axial dispersion.

*35. Berger RJ, Pérez-Ramírez J, Kapteijn F, Moulijn JA: Catalyst performance testing: bed dilution revisited. Chemical Engineering Science 2002, 57:4921-4932.

Excessive bed dilution can lead to a non-ideal contacting pattern at high conversions.

36. Berger RJ, Pérez-Ramírez J, Kapteijn F, Moulijn JA: Catalyst performance testing: Radial and axial dispersion related to dilution in fixed-bed laboratory reactors. Applied Catalysis A: General 2002, 227:321-333.

37. Alpay E, Kershenbaum LS, Kirkby NF: Pressure correction in the interpretation of microreactor data. Chemical Engineering Science 1995, 50:1063-1067.

38. Pérez-Ram'irez J, Berger RJ, Mul G, Kapteijn F, Moulijn JA: The six-flow reactor technology: A review on fast catalyst screening and kinetic studies. Catalysis Today 2000, 60:93-109.

39. Al-Dahhan MH, Dudukovic MP: Catalyst wetting efficiency in trickle-bed reactors at high pressure. Chemical Engineering Science 1995, 50:2377-2389.

40. Hickman DA, Weidenbach M, Friedhoff DP: A comparison of a batch recycle reactor and an integral reactor with fines for scale-up of an industrial trickle bed reactor from laboratory data. Chemical Engineering Science 2004, 59:5425-5430.

*41. van Klinken J, van Dongen RH: Catalyst dilution for improved performance of laboratory trickleflow reactors. Chemical Engineering Science 1980, 35:59-66.

This paper offers one of the earliest examples that clearly demonstrates the effectiveness of bed 
dilution with inert fines to enable essentially complete catalyst wetting in a laboratory scale trickle bed reactor.

42. Al-Dahhan MH, Dudukovic MP: Catalyst bed dilution for improving catalyst wetting in laboratory trickle-bed reactors. AlChE J. 1996, 42:2594-2606.

43. Hickman DA, Holbrook MT, Mistretta S, Rozeveld SJ: Successful Scale-up of an Industrial Trickle Bed Hydrogenation Using Laboratory Reactor Data. Industrial \& Engineering Chemistry Research 2013, 52:15287-15292.

44. Tsamatsoulis D, Al-Dahhan M, Larachi F, Papayannakos $\mathrm{N}$ : The effect of particle dilution on wetting efficiency and liquid film thickness in small trickle beds. Chemical Engineering Communications 2001, 185:67-77.

45. Kan K-M, Greenfield PF: Multiple Hydrodynamic States in Cocurrent Two-Phase Downflow through Packed Beds. Industrial \& Engineering Chemistry Process Design and Development 1978, 17:482485.

46. Sederman AJ, Gladden LF: Magnetic resonance imaging as a quantitative probe of gas-liquid distribution and wetting efficiency in trickle-bed reactors. Chemical Engineering Science 2001, 56:2615-2628.

47. van der Merwe W, Nicol W: Characterization of Multiple Flow Morphologies within the Trickle Flow Regime. Industrial \& Engineering Chemistry Research 2005, 44:9446-9450.

48. Loudon D, van der Merwe W, Nicol W: Multiple hydrodynamic states in trickle flow: Quantifying the extent of pressure drop, liquid holdup and gas-liquid mass transfer variation. Chemical Engineering Science 2006, 61:7551-7562.

49. van Houwelingen AJ, Sandrock C, Nicol W: Particle wetting distribution in trickle-bed reactors. AlChE Journal 2006, 52:3532-3542.

50. Baussaron L, Julcour-Lebigue C, Wilhelm A-M, Delmas H: Wetting topology in trickle bed reactors. AlChE J. 2007, 53:1850-1860.

51. van der Westhuizen I, Du Toit E, Nicol W: Trickle flow multiplicity: the influence of the prewetting procedure on flow hysteresis. Chem. Eng. Res. Des. 2007, 85:1604-1610.

52. Maiti R, Atta A, Nigam KDP: Effect of Particle Porosity on Hysteresis in Trickle-Bed Reactors. Ind. Eng. Chem. Res. 2008, 47:8126-8135.

53. Dwivedi PN, Upadhyay SN: Particle-Fluid Mass Transfer in Fixed and Fluidized Beds. Industrial \& Engineering Chemistry Process Design and Development 1977, 16:157-165.

54. Chilton TH, Colburn AP: Mass Transfer (Absorption) Coefficients Prediction from Data on Heat Transfer and Fluid Friction. Industrial \& Engineering Chemistry 1934, 26:1183-1187.

55. Satterfield CN: Heterogeneous Catalysis in Practice. New York: McGraw-Hill; 1980.

56. Smith JM: Chemical Engineering Kinetics. New York: McGraw-Hill; 1981.

57. Kärger J, Ruthven DM: Diffusion in zeolites and other microporous solids: Wiley; 1992.

58. Satterfield CN, Colton CK, Pitcher WH: Restricted diffusion in liquids within fine pores. AlChE Journal 1973, 19:628-635.

59. Aris R: On shape factors for irregular particles--I : The steady state problem. Diffusion and reaction. Chemical Engineering Science 1957, 6:262-268.

60. Weisz P, Prater C: Interpretation of measurements in experimental catalysis. Adv. Catal 1954, 6:60390-60399.

61. Satterfield CN: Mass transfer in heterogeneous catalysis: M.I.T. Press; 1970.

62. Weisz PB, Hicks JS: The behaviour of porous catalyst particles in view of internal mass and heat diffusion effects. Chemical Engineering Science 1962, 17:265-275.

63. Weisz PB, Swegler EW: Effect of Intra-particle Diffusion on the Kinetics of Catalytic Dehydrogenation of Cyclohexane. The Journal of Physical Chemistry 1955, 59:823-826. 
64. Sharma RK, Cresswell DL, Newson EJ: Kinetics and fixed-bed reactor modeling of butane oxidation to maleic anhydride. AIChE Journal 1991, 37:39-47. 